
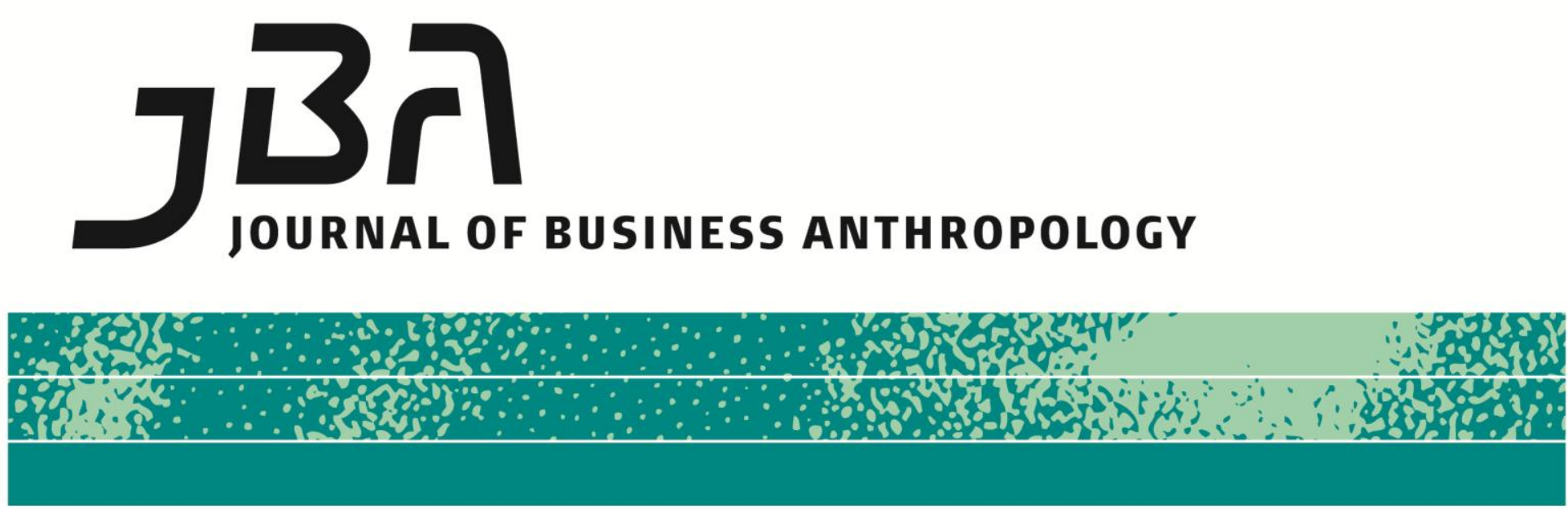

\title{
Ethnographic strategies for making the familiar strange: Struggling with 'distance' and 'immersion' among Moroccan-Dutch students
}

Machteld de Jong, Frans Kamsteeg, and Sierk Ybema

\begin{abstract}
Ethnographic fieldwork is a balancing act between distancing and immersing. Fieldworkers need to come close to meaningfully grasp the sense-making efforts of the researched. In methodological textbooks on ethnography, immersion tends to be emphasized at the expense of its counterpart. In fact, 'distancing' is often ignored as a central tenet of good ethnographic conduct. In this article we redirect attention away from familiarization and towards 'defamiliarization' by suggesting six estrangement strategies (three theoretical and three methodological) that allow the researcher to develop a more detached viewpoint from which to interpret data. We demonstrate the workings of these strategies by giving illustrations from Machteld de Jong's field- and text-work, conducted among Moroccan-Dutch students in an institution of higher vocational education.
\end{abstract}

\section{Keywords}

Ethnography, immersion, estrangement, Moroccan students, fieldwork.
Page 1 of 19

JBA 2(2): 168-186 Fall 2013

(C) The Author(s) 2013 ISSN 2245-4217

www.cbs.dk/jba 
Ethnographic fieldwork typically involves the development of close connections between the fieldworker and subjects and situations being studied (Hammersley and Atkinson 2007; Lofland 1995; Prasad 2005). To understand what the anthropologist Malinowski first called the 'native's point of view', ethnographers need to be 'living with and living like those who are studied' (Van Maanen 1988: 2, 49, 50). However, while 'immersion' is generally acknowledged as a central feature of good ethnographic field research, its logical counterpart, 'distancing', is a neglected topic in methodological textbooks which usually only offer the obligatory warning 'not to go native'. As we have argued elsewhere (Ybema and Kamsteeg 2009), 'distance' is equally as important as 'closeness' for an adequate understanding of the 'natives' and, indeed, becomes crucial precisely at the point a researcher gets immersed in the field. As Prasad (2005: 81) points out: 'when ethnographers share many elements of a culture with the natives under observation, they may find it hard to notice the more taken-for-granted aspects of the culture itself. Researchers who do their fieldwork not in some isolated tribe but in their own global village are much closer to their 'natives' than anthropologists traditionally used to be, if only because the researched are often physically or virtually 'within reach'. Consequently, the fieldworker's strategy must be 'making the familiar strange rather than the strange familiar' (Van Maanen 1995: 20).

Strangeness is what traditionally made an unknown culture attractive, just as a desire to bridge that strangeness through familiarization created the attractiveness of ethnographic writings. In these, strangeness is the given, and immersion in the field should counter it. However, when 'ethnographying' (Tota 2004) situations strongly familiar to us, strangeness is not a given but something researchers can only achieve by finding the proper strategies to uncover what-is-not-sonormal, because the very 'un-strangeness' of their research environment prevents them from seeing it. In this sense, researchers are like fish trying to discover the water that surrounds them. And we might argue that they need to develop their amphibian skills by, physically or mentally, going in and out of the water. So, if ethnographic research today entails studying those 'close by' rather than some distant 'other', how do we avoid getting bogged down in a myopic gaze or becoming blinded by the overly familiar? And, if 'there is nothing as seductive for the fieldworker as being made to feel like an insider' (Kunda 1992: 236), how do we step back and make sense of the situation from an outsider's perspective (Fetterman 1998: 11)?

Organizational ethnographers are often relatively close to the field being studied, both socially and culturally. They tend to solve problems of access by drawing on connections in their personal networks, studying 
sites that are familiar to them, and thus becoming professional insiders or even full members of the organization. In doing so, they substitute the boundaries that first kept them out with those that keep them in, thus facing the problem, as Mosse (2006: 936) put it, 'not of entering a different world so as to be able to imagine or infer the taken-for-granted ... but of exiting a known world for the same purpose' (our emphases).

The structure of this article is as follows. First, we argue that ethnographic understanding develops through getting close to the organizational field, while simultaneously preserving the distance that will foster a capacity for the ongoing experience of surprise. This approach calls for a dual stance on the part of the researcher: being both immersed and estranged, thereby holding on to a basic wonder about the unexpected, the noteworthy, and the counter-intuitive of everyday 'normality' and its governing rules (Pickering 2001: 174ff). As we think 'estrangement' in particular needs further reflection, we then describe a number of strategies through which fieldworkers can try to stimulate the interplay between distanced interpretation and immersed observation. We explore, among other things, the roles of surprise, paradox, play, and irony. To illustrate, and critically reflect on the estrangement strategies, we describe how de Jong did her fieldwork on identity formation of Moroccan-Dutch higher education students. We will show how she was constantly switching roles, between insider-outsider, friend-visitor, teacher-researcher, and so on: a chameleonic positioning which was sometimes emotionally stressful, and at other times even painful.

\section{Involvement and detachment: a difficult match}

A proclaimed strength of ethnographic research is its capacity to tap into ordinary life, describe it in depth and in detail, and develop an understanding 'from within'. Organizational ethnography can in this way be seen as the art of exploring the complexities of everyday organizational life through immersion (Koot 1995; Koot et al. 1996). Yet, at the same time, 'complexity' and 'everydayness' also pose problems for the 'immersed' researcher. The variety of field observations and the intensity of experiences when studying organizations 'up close and personal' is often confusing to such an extent that fieldworkers either get 'lost' in the complexities of the field, or are caught up in the 'everydayness', the 'infra-ordinary' (Perec 1989), of organizational life. Researchers often assume that inside members are incapable of understanding the rules of their own 'show', but why would the immersed researcher not be susceptible to the same 'blindness'? After all, everyday organizational life is often tedious and tends to become ever more uninteresting as the researcher becomes 'part of the furniture'.

While researchers often accept immersion in the field uncritically as an inherent quality and unproblematic asset of in-depth organizational research, they tend to ignore, downplay, or denounce the importance of 
distancing. Shotter, for instance, criticizes theorizing 'from the outside' (2006: 585) while wholeheartedly embracing 'thinking-from-within' or 'withness-thinking'. This 'thinking-from-within' is what many claim to be ethnography's main purpose and strength (e.g. Prasad 2005; van Maanen 1988). It prioritizes the context-specific, or 'experience-near' (Geertz 1983) over 'experience-distant' 'aboutness-thinking'.

We concur that long-term engagement with those studied and understanding cultures 'from within' are crucial for ethnographic research. However, openness and empathic understanding should go hand in hand with 'a constant urge to problematize, to turn what seems familiar and understandable upside down and inside out' (CzarniawskaJoerges 1992: 73). For practitioners of organizational ethnography, 'utilizing familiarity' is as important as 'working on strangeness' (Neyland 2008: 101-02). Yet this is far from easy, as Becker (quoted in Hammersley and Atkinson 1995: 103) reminds us: 'It takes a tremendous effort of will and imagination to stop seeing only the things that are conventionally "there" to be seen'. Being 'intellectually poised between familiarity and strangeness' (Hammersley and Atkinson 1995: 112), ethnographers should variously take up the role of insider and outsider (Duijnhoven and Roessingh 2006), oscillating between the 'external' view of the observer and the 'internal' view of the participant, between 'zooming in' and 'zooming out' (Nicolini 2009), thus mediating 'experience-near' and 'experience-far' concepts when analysing findings (Geertz 1973; Marcus and Fischer 1986).

Acknowledging the importance of our role as a 'relative outsider' to the field includes allowing ourselves to experience feelings of unease and accepting a 'painful sense of separation between the observer and the observed' (Lofland and Lofland 1995: 52). The discomforting experience of being 'not one of them', or of feeling conflicting loyalties, does not necessarily need to be avoided or replaced by a more comfortable sense of feeling 'at ease' or being 'one of them' (Hammersley and Atkinson 1995: 114-17). Quite the contrary. Without wanting to romanticize the frustrations that come with doing fieldwork, we believe that confusion, estrangement, loneliness, wonder, annoyance, and any other distancing emotion experienced during fieldwork, while hardly joyful, can be vital sources of inspiration for a researcher. These emotions put the researcher at a reflexive distance from the field, a marginal position from where s/he may see things differently (Wels, v.d. Waal, Spiegel \& Kamsteeg 2011). For these reasons, the sense of alienation and 'strangeness' experienced by the fieldworker can be seen as an intrinsic and important component of good ethnography, a critical companion or counterpart to the widely acclaimed and well-described ethnographic tenet of establishing a 'deep' or intimate familiarity with the field of study (Lofland 1995; Lofland and Lofland 1995). As researchers we should somehow preserve the newcomer's capacity for wonderment and adopt a habitus of surprise. Paradoxically, we are able to understand and describe the field from the 
inside out only if we approach it, in some way or another, from the outside in.

\section{Strategies for keeping distance - and yielding surprise}

What 'tools' or strategies do we have to preserve our initial wonder about seeming contradictions and irrationalities, and to avoid becoming a myopic participant reproducing emic 'truths'? How do we develop a distanced, reflexive stance that enables us to denaturalize the field's taken-for-granted understandings and to foster readers' surprise?

To explicate and illustrate how surprise may produce unexpected insights and interpretations in organizational ethnographic research, we draw on Machteld de Jong's research experiences. We outline various instances of distancing and yielding surprise, framing her experiences with 'distancing' in six strategies that we have described elsewhere (Ybema and Kamsteeg 2009). First, we describe three strategies of theoretically informed interpretation (subsections one, two, and three below) that show some of the ways in which theory and distanced analysis may play a role in disengaging the immersed researcher. Second, we explore three strategies of observation (sections four, five, and six) that suggest various ways in which researchers may take advantage of an insider/outsider role. We read all six strategies as efforts to take a 'disengaged engaged position' that tries to keep the organizational ethnographer open to maintain, to develop, and to convey surprise. In order to be able to understand the six strategies, we start with a brief indication of the research theme and its fieldwork base.

\section{Struggling with 'distance': fieldwork among Moroccan students}

In I am not that kind of Moroccan! I (Machteld de Jong) described how Moroccan-Dutch students of a Dutch Institute for Higher Vocational Education construct their identity in a variety of contexts. Over a period of six years I followed or 'shadowed' (Czarniawska 2007) over a hundred students in their educational career. My involvement as a teacher of these young students was an important motive to do this research. I was intrigued by the fact that these hard-working students largely remain 'invisible' in the popular as well as the scientific press. The unobtrusiveness of these 'normal' students strongly contrasts with other Moroccan-Dutch youth, who are extremely present in the news because of criminal or other cross-border behaviour. Perhaps we could say that one group is suffering from a negative self-image as a result of the behaviour of the other group (see, for example, Social and Cultural Planning Bureau $2007 ; 2009 ; 2010$ ). The result is a negative image of the whole Moroccan group in Dutch society. This misrepresentation of the Moroccan youth became for myself, who was also teaching this group, a stimulus to look for a more encompassing image and make the voice of this invisible group 
heard. My personal life history was a further motivation to identify myself with my research group. As a first-generation student myself, my sometimes complex relationship with my parents had fed my determination to pursue a better education than they had received. Hence, as a teacher I was fairly sensitive to my students' study drive, which resulted in a position almost opposite to that of the 'professional stranger' (Agar 1980).

Familiarity and recognition gave me many advantages in gaining access. As other researchers have described, trying to get inside a Moroccan community, known for its staying restrained from its environment, meets with a lot of distrust on the part of Moroccan mothers (Jonkers 2003; Van den Berg 2007), Moroccan problem youths (Werdmölder 2005; De Jong 2007), or problem families (Kleijwegt 2005; Jurgens 2007). As a teacher of Moroccan-Dutch students, I did not have access problems: I was surrounded by students every day. Besides the initial core of 40 Moroccan-Dutch students that I selected for my study, other students quickly 'volunteered' to participate in the research, mainly driven by the urge to 'finally' tell their own story and contradict what was presented in 'the media' about the Moroccan-Dutch. This gave me a vast reservoir of informants with whom I could share and 'check' my findings and insecurities at any time.

Yet, during the research I was frequently torn back and forth between the role of an 'insider' and the 'outsider's' role required for critical analysis: involvement constantly competed for priority with reflexivity. Because of my familiarity with the student population, distancing myself from the research group was - literally and figuratively - a much bigger problem than gaining access (see Berg 2001: 136-139; Ybema and Kamsteeg 2009: 112). I knew that I would never totally become one of them, despite all my knowledge of, and involvement with, the Moroccan-Dutch population group. However, I was well aware that I had to work hard to even avoid going 'near-native'.

Balancing distance and immersion in my fieldwork was never settled once and for all. In fact, I struggled throughout my fieldwork to be sufficiently 'close' and 'distant'. Consciously, and sometimes unconsciously, I deployed several strategies for keeping professional distance. In this article, I use Ybema and Kamsteeg's discussion of six strategies - three theoretical and three methodological strategies - to reflect on my positioning in the field with the purpose of creating detachment.

\section{Strategy 1: Holding and breaking mysteries}

Various ethnographers have stressed that a researcher needs to surprise him/herself constantly, and should continuously be looking for the unexpected, the 'mystery' (Alvesson and Kärreman 2006; Agar 1986; 
Schwartzman 1993). Schwartzman (1993: 68) suggests that '[m]ystery ... is a good place to begin field research', because it creates a focus on 'the unanticipated and unexpected - things that puzzle the researcher' (Alvesson and Kärreman 2006: 1266). Reflexive distance can be achieved in two ways, either from building on our own surprise or on surprises experienced by the researched. Agar (1986) urges ethnographers to adopt an 'anti-coherent attitude' in which 'understanding is suspect; you self-consciously try to show that 'what I think is going on probably isn't" (Agar 1986: 50). Following Agar, Alvesson and Kärreman (2006) suggest that researchers seek to discover a mystery, or construct one themselves, incubate it throughout the research, and, finally, present it as a novel, theoretically grounded and significant result.

As a teacher, I strongly identified with my Moroccan-Dutch students and I accepted their message that they were put in a disadvantaged position by the constant stream of negative reporting on Moroccans in the public debate. Perhaps somewhat naively, I embraced this perspective, which gradually became part of my scientific drive. I became convinced that my growing knowledge about this group of youths might provide the ammunition for a scientific argument that could support a more accurate and nuanced view of Moroccan-Dutch youth. This became the scientific mission that guided my 'innocent' interpretations of student behaviour. Along the way, however, I had to reflect on the advocacy position that was so precious to me. My supervisors pressed me to this 'interpretation of interpretation' (Alvesson and Skölberg 2000: 6), as did my students themselves, who became slightly irritated by my all-too-understanding interpretation of their behaviour. Female informants, in particular, emphasized that I might well open my eyes to what had gone wrong in, for instance, the unequal relationship between Moroccan men and women. As one girl said to me:

"Machteld, I read your text and you should really be more critical. You don't need to have understanding for everything. Just write down how it is when it comes to Moroccan men and women, to the role of parents in the life of their children, and to the strong gossiping."

Thus my initial, self-constructed mission suffered a few heavy blows and I met the boundaries of my tendency towards 'understanding'. I was forced to distance myself, being faced with a mystery, because I seemed to understand my students far less than I thought I did. My rosy picture of them almost forced the Moroccan-Dutch youths to show less positive images of themselves.

In this same period, I was not only pushed away from emphatic understanding and into distancing, I also began to feel distanced from my students. I started to realize that my position of insider and companion was untenable. The stories and events the students shared with me, beautiful as they might be, made it sometimes painfully clear to me that in 
the end I really did not belong to their world - either as a researcher, or as a person. This experience brought on feelings of confusion, annoyance, and sometimes frustration. I slowly started to realize that I was the cause of these feelings myself. I wanted to build a 'beautiful' image of MoroccanDutch youths and to recognize commonalities rather than differences between students and myself and my own 'emancipation-oriented' life. I was confronted by my own biases.

An example: once I went to visit a student who had indicated to me that she was having personal problems at school. After a difficult and violent marriage, her mother had decided to get divorced from her father. The student lived together with her mother and three brothers in an apartment on the top floor in the Amsterdam West district. Her mother had become seriously depressed and was lying on the sofa all day long. The student took care of her and had frequent conversations with her about the hardships of life. She glowingly told me that she wanted to finish her education and that she dreamt about a beautiful future after getting her diploma. I confronted her with the fact that she was always complaining, and often didn't show up either to my lectures or to the project meetings. I tried to motivate her and to convince her that by putting a bit of effort into it and working hard she could achieve more. I noticed that I couldn't convince her. She kept hiding behind vague excuses. My visit ended in disappointment. Apparently, I wasn't able to motivate the student and to bring some structure to her life as she found everything 'hard and complicated.' Half a year later she gave up her study because of 'personal circumstances'.

This case shows that fieldworkers may run the risk of overempathising with the researched and thus becoming socially bound up with their field sites, particularly when they delve into contexts that they already sympathized with beforehand. Being confronted with her own biases and compassion, the researcher first had to go through a painful process of distancing herself from the field. Much to the advantage of the research, however, this created the preconditions for a challenging mystery. She had to rethink her own assumptions and interpretations, and to ask questions anew. In this sense, she had to 'mystify' her students and their behaviours, and thus to learn to see a familiar landscape with new eyes.

\section{Strategy 2: Looking for the 'irrational'}

In the previous section, we reflected on the mystery-making of the researcher as a strategy for distancing. Another strategy to create distance is to search for the irrational or 'strange' in the behaviour of the researched (Ybema and Kamsteeg 2009; see for an example, Ybema, Vroemisse and Van Marrewijk 2012). As we shall see in the case description below, different ethical principles and forms of behaviour between the ethnographer and the 'ethnographied' not only create moral 
dilemmas (Fine and Shulman 2009); they also serve to produce fruitful estrangement.

In daily relationships with students, I encountered quite some (in my view) 'unethical' and 'irrational' behaviour. Incidents of malicious gossip, deceit, and theft regularly created doubts about our relationship and my interpretations of my protagonists. For example, in 2008, I supervised two female Moroccan-Dutch students for their graduation research. They worked hard and my contact with them was pleasant. Yet, both of them still had some exams to pass and they were not particularly looking forward to them. Prior to their examination period, it appeared that one of the exams had been stolen. When marking papers, I realised that a group of students, among whom were my two students, had produced suspect answers. Everybody denied having anything to do with the theft. When I talked to the two students, they swore they had nothing to do with the situation. Yet, after graduation, I discovered that they had seen the exam via one of their fellow students. I realised that fear of failing the exam and not receiving a diploma (and, consequently, of not being able to start studying at university) would have caused a huge loss of face in these students' families. Apparently, this weighed heavier on them than the risk of suspension and their honesty towards me. Later on, I heard from other students that the two girls still felt very ashamed towards me, yet also thought that they made the right decision to let their own interests prevail.

How was I to understand this 'strange' behaviour, where the students not only went against their own principles, but also 'betrayed' me? I felt hurt and puzzled. I questioned the ethics of their behaviour, something I had rarely ever done before. In some fierce group discussions about study ethics, the students subtly made it clear to me that for them the end (a diploma and future job) sometimes justified the means to achieve it. As one of the male students explained:

"I just want to reach my goal, get what is best for me. Of course, I feel guilty sometimes if it comes to certain behaviour, but if it goes unnoticed, it doesn't really matter to me either; I only think about my diploma. Maybe a bit egoistic, but at such moments I don't permit myself to start thinking about morals."

Although, rationally, I was able to understand the calculative logic of his behaviour, I failed to grasp its substantive rationality. The confrontation with such 'irrational' and 'unethical' behaviour, while testing my beliefs and sympathies, gradually made me realise I had to be more critical about what I had thus far considered 'true' information. I had to view my protagonists with new eyes.

Evidently, moving from immersion to distancing can be a painful process. A fieldworker's wish to understand them 'from within' and to become 'one of them' may make him or her overly understanding, taking what research participants say at face value. In this case, an ethical clash 
taught the fieldworker to regain a more distanced viewpoint and to be alert to 'strange' behaviour.

\section{Strategy 3: Making it look strange}

For making overly familiar data look strange again, researchers may pursue a data-driven strategy by looking for the irrational in participants' behaviour, but they may also adopt a theory-driven strategy and use 'strange' concepts to make sense of apparently normal behaviour, thereby creating an 'alienating' effect. The immersed fieldworker might then 'distance' or 'defamiliarize' him/herself from the field by using figures of speech, both in theorizing and in writing, so as to make the ordinary sufficiently 'strange' for presentation (Hammersley and Atkinson 2007: $191 \mathrm{ff}$.). This can be done, for instance, by applying psychologising concepts to pseudo-rational worlds of management (Ybema 2003), or anthropological concepts acquired through studies of far-away societies (for instance, 'the natives', 'tribe', 'ritual', and so on) to our own society of organizations (Marcus and Fischer 1986: 137ff; see also Kamsteeg \& Wels 2004).

When I read Bourdieu's field theory (1977), I realized that his ideas might help me analyse Moroccan-Dutch student identity. I accustomed myself to viewing the students as 'field players' with various amounts of 'capital'. I was so 'successful' in this that even in field situations this image made me sometimes forget that the students were still people of flesh and blood. Labelling students and situations using Bourdieu's terms of 'field player,' 'capital,' 'habitus' and so on became a conscious way of making them 'strange'. The downside of this 'success' was that it evoked contradictory feelings of discomfort and uneasiness about reducing people whom I esteemed as meaning-making human beings to just 'vessels' for concepts. One way of coping with this ambivalence was to explain to the students how I interpreted their behaviour in theoretical terms. Often they were surprised when I told them about my theorizing. It became clear to them that, although I interacted with them on a daily and almost friend-to-friend - basis, I was also a theorizing researcher. In this role I was clearly not as close to them as in my teacher role which they knew, and often preferred. To some extent, therefore, theorizing alienated me from the students who were otherwise so close to my teacher's heart, while it simultaneously allowed me to engage in a more distanced analysis of their everyday practices.

Social scientific theorizing captures social worlds in terms that are often alien to the people inhabiting those worlds. Such 'etic' terms place researchers at an interpretive distance from the field, allowing them to see the field from a different perspective. Having described three theoryinformed interpretive strategies for de-familiarization, we now turn to three more methodologically-focused ways to reach the same defamiliarising effect. Through strategies of observational role-taking, 
organizational ethnographers may adopt these in the field in order to disengage and distance themselves from it.

\section{Strategy 4: Breaking the friendship bond}

One strategy for regaining reflexive, and physical, distance is through literally moving out of the field, thus creating a breach in the often intimate relations with those researched. The fieldworker might also consider successive immersions and retreats by regularly moving in and out of the field (Niccolini 2009), or by moving between different, even contrasting sites (Kamsteeg 1998), and talking to other parties involved. This is how Machteld applied this strategy:

As often happens in ethnographic research, a personal, almost friendly, relationship developed between me and a number of the students, one that in some cases was maintained after I finished my research. We shared beautiful experiences - like the joy over their first job, their marriage, or the birth of their children. Yet, we also shared sad moments, like the death of a parent, marital difficulties, and illnesses. Consciously breaking friendly relations so as to create distance was not an option if only because I met most of them at school almost daily. During the completion phase of the research, when I did not lecture for half a year, contacts continued. For them, I was the teacher 'whom you could always approach'. When they felt lonely or had problems, many of them tried to get in touch with me, also during evenings and at the weekend. They just did not permit me to 'step out of the field'.

Take the following example: one student had told me that, because of his father's severe illness, he had difficulties controlling his aggression. Sometimes he just walked into the street in search of a fight with a random passer-by. I told him to contact me whenever this threatened to happen. As a consequence, he regularly called me at the most untimely hours. Yet I always made sure to answer the phone, even if it was in the middle of the night, as I feared he might panic and misbehave.

In this kind of case, I decided not to limit our friendship, but on other occasions I did try to keep my distance from 'Moroccan customs'. For example, when a participant was getting married, I often went to the wedding. However, I never participated in the so-called 'henna nights' for female friends and family members. These nights often lasted from the beginning of the afternoon till the late evening when the hands of the future bride were covered with henna so as to keep away angry ghosts that could stand in the way of her luck. By skipping this 'ritual', I suggested that my friendship was not unlimited. I did not always do things their way. During visits to their homes, I also deviated from the normal pattern. Moroccan visits tend to be lengthy. Sometimes family members even stay for the whole day. Out of self-protection and lack of time I tried to 'limit' my visits by moving along after three or four hours 
(!). Sometimes my informants/friends would be disappointed, saying 'are you leaving already?', although my 'compromise' occasionally elicited understanding, too. Still, this kind of time management always felt like a delicate balancing act, never being entirely sure whether or not I had stayed long enough not to hurt the feelings of students and their families.

Although, in this case, relationships were too close to break friendship bonds, Machteld's 'Dutch' way of giving substance to friendship - limiting her participation in rituals and visits - kept her from 'going native', preserving distance for analysis and observation.

\section{Strategy 5: Distancing by immersion}

Reflexive distance and refreshing one's sense of surprise can be achieved by literally leaving the circle of informants, but the opposite strategy might also be pursued. An example of ethnographic work creating surprise through deeper immersion rather than through distancing can be found in studies describing tensions between front-stage appearances and back-stage processes (see, for example, Goffman 1983; Whyte 1948). Instead of (literally) distancing oneself from the researched, the strategy pursued here is that of 'extreme' immersion.

During my research I was regularly told that I was starting to think like a Moroccan ('you really know how things work among us'). During the first couple of interviews with students, I was sometimes fobbed off with smooth, front stage stories, rather like what Jonkers (2003) experienced during interviews for her study of Moroccan mothers. Yet, when we started to see each other more often, I dared to push aside the curtain hiding the backstage, and managed to see and hear more than non-intimates were supposed to know.

For instance, a student whom I had already interviewed a few times once came to my room to discuss his study situation. I had to pick up something from a colleague's office, so I asked him to wait a moment in my office. The student, seeing my bag, immediately urged me to take my iPhone out, explaining: 'Now that I've seen it in your bag, I wouldn't be able to resist pick-pocketing it when you leave, and run before you're back. It just feels like a temptation, like setting the fox to watch the geese.'

Like her colleagues, Machteld closed her door whenever leaving her office. Frequent pilferage forced her into this routine. Being confronted by a student who admitted to, and warned her against, his own inclination to steal, gave pilferage a face: the face of one of her participants. By getting really close to him, and making him sympathize with her, she found out socially undesirable aspects of his thoughts and behaviour which otherwise she would never have suspected. So, paradoxically, fully immersing oneself in the field may lead to alienating insights. On other occasions as well, students' openness about their behaviour helped her to lose her rosy illusions about her students (see also the example of 
cheating on an exam under 'strategy 2'). Getting really close to people sometimes allows one to discover and know for sure that, in front stage appearances, they are 'bullshitting'.

\section{Strategy 6: Playing the jester}

A final methodological strategy to make-the-familiar-strange might be to benefit from the sense of irony and playfulness typical of fools, clowns or comedians who subvert normality by offering an 'upside-down perspective' on social life. Perhaps organizational ethnographers should more often consider playing the role of the 'organizational fool' as described by Kets de Vries (1990). Kets de Vries was inspired by the figure of the royal court jester in a play like Shakespeare's Twelfth Night. Historically speaking, these royal fools became ever more servile extensions of the king (Zijderveld 1982) - petty clowns within the king's inner circle who re-confirmed rather than upset normality. However, with Kets de Vries, we favour the mythologized version of the jester as the king's critical sparring partner, subtly correcting his master by playing an unveiling, beguiling, bridging and bonding role, thus 'balancing a leader's hubris' (Kets de Vries 1990: 751). Unlike jesters, ethnographers tend to take themselves and their work rather seriously (Driessen 1996; Douglas 1975). And so, this playful role is not a cloak that always fits easily.

Humour can be powerful, but its use in fieldwork relations is not without risks. I did not want to hamper my reputation as a (serious) teacher. And being a member of a cultural majority made joking with ethnic minority members especially sensitive. For instance, what De Jong (2007) thought to be an innocent joke about the mother of one of his Moroccan boy informants turned out to be a 'wrong' joke which hurt the boys' feelings. A 'joking relationship' between people with different (power) positions can be tricky and risky (for example, Veale 2004). Sometimes, the atmosphere could be somewhat uncomfortable and 'unhumorous' when, for instance, students' parents wanted to correct stereotypical images of the Moroccan-Dutch as 'bad parents' and 'dole claimers' - mothers stressing how well-behaved their children were compared to their Dutch fellow students, or fathers emphasizing that they would never accept living on the dole. Given the sensitivity of MoroccanDutch to negative attention in public debates, I frequently asked myself: am I, or am I not, 'licensed' to make a joke? Showing too ironic a demeanour, or breaking too many politically sensitive taboos, might estrange me from the students instead of producing a productive distance. The tragic fate of some of yesteryear's jesters might become mine.

However, at some moments humour did make the 'unfamiliarity' and cultural 'otherness' visible and acceptable, helping to appreciate, and to establish connections beyond, existing differences. I was particularly fond of making jokes about 'the' Moroccan culture, such as the enormous 
piles of food offered to me during visits. A simple joke suggesting that during my doctoral research I had gained five kilos was a subtle way of making clear that I was 'not like them'. I made similar kinds of jokes stressing cultural differences during conversations with female students and their mothers - for instance, about the mother-in-law role or the Moroccan female passion for gossiping. In a similar vein, I also joked with participants about 'the Dutch'. For instance, I did not conform to the stereotype of Dutch families limiting themselves to presenting one single cookie to visitors, routinely closing the tin afterwards. When receiving students at home, I offered food in abundance and I then made jokes on my 'un-Dutch' or 'Moroccan' habit of putting piles of food on the table. I would also joke about the 'shameful' way the Dutch do away with their elderly parents in rest-homes. Although my students could be quite serious about this, I permitted myself to engage in self-mockery, while putting on an ironic smile, thus suggesting that I was with them, but not quite. This way, playing with cultural stereotypes re-affirmed cultural differences, without taking them overly seriously and thus reducing social distance.

The 'jester-like' strategy shows that researching organizational processes is not necessarily or always best done in a serious manner. Without turning the organizational ethnographer into a cabaret figure, the examples show that adopting some of the jester's use of humour and irony can lighten up over-serious ethnographers (see, for similar views, Douglas 1975; Driessen 1996; Johansson and Woodilla 2005), as well as over-serious researcher-researched relationships. The confronting effects of jester-like behaviour can help out organizational ethnographers in their search for professional strangeness.

\section{SPQR: Sono pazzi questi Romani}

Fieldworkers run the risk of becoming socially bound up with their field sites and thus becoming increasingly drawn into that field's rationalities and singularities. Ethnographers who try to give in-depth and withnessdriven accounts of the riches of everyday experience, based on their longterm engagement in the field, should be aware of the risk of losing distance and adopting the member's poor awareness of his or her own culture. Precisely in order to really understand 'the native's point of view', they would do better to preserve a reflexive distance, and devise strategies that help to secure a sufficient amount of 'aboutness' in their writings. This is why we suggest that organizational ethnographers cherish their place on the margins of organizations and stay somewhat marginal, entering the field with an almost naive wonder about the way people think and act in organizations, and maintaining their engaged, yet simultaneously distanced, playful, and at times ironic stance. To generate data, develop interpretations, and represent findings, ironies and mysteries that come up in the interplay between data and theory and 
between the researcher and the researched can be rich sources of inspiration. Seeing the extraordinary-in-the-ordinary may help to elicit curiosity about people's 'strangeness', as well as challenge the taken-forgranted logic of things: 'theirs' as well as 'ours'.

In this article, we have discussed ways in which fieldworkers may support the playfulness, ironic stance or 'wondering distance' while being immersed in the field. The various 'strategies' could have been complemented with, for instance, Garfinkel's (1967) 'rule-breaking'; Burawoy's (2003) 'time-outs'; Bartunek and Louis's (1992) insideroutsider research teams; or Bourdieu's (1992) understanding of reflexivity. All these strategies have in common the fact that, in various ways, they meet the researcher's obligation to maintain or regain the surprise of a newcomer, so poignantly summarized in the words spoken by the French comic hero Obélix every time he met a group of (Roman) soldiers: 'These Romans are crazy!'

\section{References}

Agar, M. H. 1980 The Professional Stranger. New York: Academic Press. Agar, M. H. 1986 Speaking of Ethnography. Beverly Hills, CA: Sage.

Alvesson, M. and D. Kärreman 2006 'Constructing mystery: empirical matters in theory development.' Academy of Management Review 32 (4): 1265-81.

Alvesson, M. and K. Sköldberg 2000 Reflexive Methodology: New vistas for qualitative research. London: Sage.

Bartunek, J.M, and Luis M. Reis 1992 'Insider/outsider research teams: collaboration across diverse perspectives.' Journal of Management Inquiry 1 (2): 101-110.

Berg, B.L. 2001 Qualitative Research Methods for the Social Sciences. Boston: Allyn and Bacon.

Berg, M. van den 2007 'Dat is bij jullie toch ook zo?'. Gender, etniciteit en klasse in het sociaal kapitaal van Marokkaanse vrouwen. Amsterdam: Aksant.

Bourdieu, P. 1977 Outline of a Theory of Practice. Cambridge: Cambridge University Press.

Bourdieu, P., and L. Wacquant 1992 An Invitation to Reflexive Sociology. Cambridge: Polity Press.

Burawoy, M. 2005. 'Revisits: An outline of a theory of reflexive ethnography.' American Sociological Review 68: 645-79.

Czarniawska-Joerges, B. 1992. Exploring Complex Organizations: A cultural perspective. London: Sage.

Czarniawska, B. 2007 Shadowing, and Other Techniques for Doing 
Fieldwork in Modern Societies. Malmö/Copenhagen: Liber/CBS Press.

Douglas, M. 1975 Implicit Meanings. London: Routledge and Kegan Paul.

Driessen, H. 1996 'Do fieldworkers laugh? Notities over humor in en over het etnografische veld.' Focaal 28: 17-27.

Duijnhoven, H, and C.H. Roessingh 2006 'The tourist with a hidden agenda? Shifting roles in the field of tourism research.' International Journal of Tourism Research 8: 115-26.

Fetterman, D. 1998 Ethnography. London: Sage.

Fine, G. A. and D. Shulman 2009 'Lies from the field: ethical issues in organizational ethnography.' In S. Ybema, D. Yanow, H. Wels, and F. Kamsteeg (eds.), Organizational Ethnography: Studying the complexities of everyday life, pp.177-195. London: Sage.

Garfinkel, H. 1967 Studies in Ethnomethodology. Englewood Cliffs: Prentice-Hall.

Geertz, C. 1973. The Interpretation of Cultures. New York: Basic Books.

Geertz, C. 1983. Local Knowledge: Further essays in interpretive anthropology. New York: Basic Books.

Goffman, E. 1983 (1959) De dramaturgie van het dagelijks leven. (The Presentation of Self in Everyday Life.) Utrecht: Bijleveld.

Hammersley, M, and P. Atkinson. 1995 Ethnography: Principles in practice. $2^{\text {nd }}$ edition. London: Routledge.

Hammersley, M, and P. Atkinson. 2007 Ethnography: Principles in practice. $3^{\text {rd }}$ edition. London: Routledge.

Johansson, U. and J. Woodilla. 'Irony - its use and potential in organization theory. In U. Johansson and J. Woodilla (eds.), Irony and Organizations: Epistemological claims and supporting field stories, pp. 25-50. Copenhagen: Liber/Copenhagen Business School Press.

Jong, J-D de 2007 Kapot Moeilijk. Een etnografisch onderzoek naar opvallend delinquent groepsgedrag van 'Marokkaanse' jongens. Amsterdam: Aksant.

Jonkers, M. 2003 Een miskende revolutie. Het moederschap van Marokkaanse vrouwen. Amsterdam: Aksant.

Jurgens, F. 2007 Het Marokkanendrama. Amsterdam: J.M. Meulenhoff B.V.

Jong, M. de. 2012 Ik ben die Marokkaan niet. Onderzoek naar identiteitsvorming van Marokkaans-Nederlandse HBO-studenten. Amsterdam: VU University Press.

Kamsteeg, F.H. 1998. Prophetic Pentecostalism in Chile: A case study on religion and development policy. London: The Scarecrow Press.

Kamsteeg, F.H. 2011 'Transformation as social drama: stories about 
merging at North West University, South Africa.' Anthropology Southern Africa 34 (1\&2): 51-61.

Kamsteeg, F.H, and H. Wels. 2004 'Anthropological perspectives on power, performance and organisational politics. 2004 ' Intervention: Journal of Culture, Organisation \& Management 1 (3): 7-26.

Kets de Vries, M. 1990 'The organizational fool: Balancing a leader's hubris.' Human Relations 43 (8): 751-70.

Kleijwegt, M. 2005 Onzichtbare ouders. De buurt van Mohammed B. Zutphen: Plataan.

Koot, W.C.J. 1995 De complexiteit van het alledaagse. Een antropologisch perspectief op organisaties. (The Complexity of the Everyday: An Anthropological Perspective on Organizations.) Bussum: Coutinho.

Koot, W., I. Sabelis, and S. Ybema 1996 'Global identity - local oddity? Paradoxical processes in contemporary organizations.' In W. Koot, I. Sabelis, and S. Ybema (eds.), Contradictions in Context: Puzzling over paradoxes in contemporary organizations, pp. 1-16. Amsterdam: VU University Press.

Kunda, G. 1992 Engineering Culture: Control and commitment in a hightech corporation. Philadelphia: Temple University Press.

Lofland, J. 1995 'Analytical ethnography: features, failures, futures.' Journal of Contemporary Ethnography 24: 25-40.

Lofland, J., and L. Lofland 1995 Analyzing Social Settings: A guide to qualitative observation and analysis. Belmont CA: Wadsworth.

Marcus, G.E, and M.M.J. Fischer 1986 Anthropology as Cultural Critique. Chicago: University of Chicago Press.

Mosse, D. 2006 'Anti-social anthropology? Objectivity, objection and the ethnography of public policy and professional communities.' Journal of the Royal Anthropological Institute 12 (4): 935-56.

Neyland, D. 2008 Organizational Ethnography. London: Sage.

Nicolini, D. 2009 'Zooming in and zooming out: a package of method and theory to study work practices.' In S. Ybema, D. Yanow, H. Wels, and F. Kamsteeg (eds.), Organizational Ethnography: Studying the complexities of everyday life, pp. 120-138. London: Sage.

Perec, G. 1989 L'infra-ordinaire. Paris: Editions du Seuil.

Pickering, M. 2001 Stereotyping: The politics of representation. New York: Palgrave.

Prasad, P. 2005 Crafting Qualitative Research: Working in the postpositivist traditions. Armonk NY: M.E. Sharpe.

Schwartzman, H.B. 1993 Ethnography in Organizations. Qualitative Research Methods 27. Newbury Park: Sage. 
Shotter, J. 2006 'Understanding process from within: An argument for "withness-thinking"'. Organization Studies 27 (4): 585-604.

Social and Cultural Planning Bureau 2007 De sociale staat van Nederland. Moerkapelle: Mantext.

Social and Cultural Planning Bureau 2009 Jaarrapport Integratie 2009. Den Haag: SCP.

Social and Cultural Planning Bureau 2010. Jaarrapport Integratie 2010. Den Haag: SCP.

Tota, A.L. 2004 'Ethnographying public memory: the commemorative genre for the victims of terrorism in Italy.' Qualitative Research 4: 131-59.

Van Maanen, J. 1988 Tales of the field: On writing ethnography. Chicago: University of Chicago Press.

Van Maanen, J. 1995 'An end to innocence: the ethnography of ethnography.' In J. Van Maanen (ed.), Representation in Ethnography, pp. 1-35. Thousand Oaks CA: Sage.

Veale, T. 2004 'Incongruity in humor: root cause or epiphenomenon? 'Humor: International Journal of Humor Research 17(4): 419-428.

Wels, H., K. v.d. Waal, A. Spiegel, and F. Kamsteeg 2011 'Victor Turner and liminality: an introduction.' Anthropology Southern Africa 34 (1\&2): 2-7.

Whyte, W.F. 1948 Human Relations in the Restaurant Industry. New York: McGraw-Hill.

Yanow, D., S.B. Ybema, and M. van Hulst 2012 'Practising organizational ethnography.' In G. Symon \& C. Cassell (eds.), Qualitative Organizational Research: Core methods and current challenges, pp. 331-350. London: Sage.

Ybema, S. 2003 De koers van de krant: Vertogen over identiteit bij Trouw en de Volkskrant. Amsterdam: VU University.

Ybema, S., and F. Kamsteeg 2009 'Making the familiar strange: a case for disengaged ethnography.' In S. Ybema, D. Yanow, H. Wels, and F. Kamsteeg (eds.), Organizational Ethnography: Studying the complexities of everyday life, pp. 101-119. London: Sage.

Ybema, S., M. Vroemisse, and A. Van Marrewijk 2012 'Constructing identity by deconstructing differences: Building partnerships across cultural and hierarchical divides.' Scandinavian Journal of Management 28 (1): 48-59.

Zijderveld, A. 1982 Reality in a Looking Glass: Rationality through an analysis of traditional folly. London: Routledge \& Kegan Paul. 
Machteld de Jong is Senior Lecturer and researcher at Hogeschool Inholland Amsterdam. Her research interest is in the identity construction of migrant youth in The Netherlands. Her current research focuses on study success of migrant youth in Dutch higher education institutions. She can be reached at machteld.deJong@inholland.nl

Frans Kamsteeg is Associate Professor in the Department of Organization Sciences at VU University Amsterdam. His research interest is in the methodology of culture and identity construction in organizational processes. He has published widely on identity formation in Latin American and Dutch organizations. His current research focuses on the cultural consequences of merging processes in South Africa's Higher Education. He can be reached at frans.kamsteeg@vu.nl

Sierk Ybema is Associate Professor in the Department of Organization Sciences at VU University Amsterdam. His research centers on processes of politics, identity and sensemaking, with empirical settings ranging from amusement parks to newspaper offices and multinational corporations. His work has been published in such journals as Human Relations, International Journal of Cross-Cultural Management, Journal of Business Ethics, Scandinavian Journal of Management, and Organization Studies. He may be reached at s.b.ybema@vu.nl 